\title{
What Future for the Renewable Energy
}

\author{
Prof. Elio Santacesaria * (Professor of Industrial Chemistry; CEO of Eurochem \\ Engineering Co.)
}

Eurochem Engineering srl, Via Codogno 5, 20139 Milano, Italy

Received April 9, 2015; Published April 10, 2015

In 1973, after the Kippur war, a considerable increase of the petroleum price occurred, because, Arabian countries decided to reduce the extraction and export of this raw material. It was the first time that petroleum price was imposed not by the market but as a consequence of a political unilateral decision. The governments of the occidental countries reacted to this situation by promoting researches on the use of coal as a possible substitute of petroleum. In Italy, for example, a national "Energy" project based on the use of coal had been launched and funded covering a period of about 10 years. Although, after some years the situation turned to the normality and the price of petroleum was consistently lowered rendering not convenient the use of coal, thanks to the performed studies, the scientists have learned to obtain from coal all the necessary components to satisfy the energetic needs. Coal was chosen as a possible alternative for the abundance of this raw material and, because, at that time the consume of petroleum was relatively limited and the environmental problems, deriving from a majestic use of petroleum, were not so important as today. In the last century, the petroleum consumption increased exponentially and the growing economy of the countries under development greatly contributed and still contributes to this increment. Gradually, the anxiety for the depletion of petroleum as raw material, which remedy could be clearly the use of coal, was substituted by the anxiety for the sustainability of the consequences of a continuous increase of the petroleum consumption on both the environment and the quality of the life. Under this aspect, coal is worse than petroleum and cannot be considered as a possible substitute.

Sustainability gradually became the cultural driving force for the development of the "Renewable Energy Sources" and new concepts like Bio-Refineries and Renewable Feedstock were diffused in a lot of publications and books and the governments funded many researches on the subject. However, it is opportune to remember that the consume of petroleum in the world is greater than 4 billion tons per year with only $4-5 \%$ destined to the chemicals production. The big economic interests, accompanying the commerce of petroleum, hold-down the development of any possible alternative. The recent intensive production of shale oil in United States, for example, has been contrasted by a strong decrease of the petroleum price produced in Arabia. In the meantime, a large availability of petroleum at low cost strongly reduced or blocked the production of bio-based fuels as biodiesel and bio-ethanol. The conclusion is that nowadays, Renewable Energy Sources cannot compete with petroleum for both the volume of production and price of the energy but remain the only feasible alternative if inserted in a revolutionary change of the way of life in which the man look for an equilibrium with the nature without renouncing to the 
wellness but certainly changing the previous habits. This is, at the same time a cultural, scientific but above all a political challenge to save the planet.

Article copyright: (C) 2015 Elio Santacesaria. This is an open access article distributed under the terms of the Creative Commons Attribution 4.0 International License, which permits unrestricted use and distribution provided the original author and source are credited. 